\title{
Zhitarenko V., Bejan V., Dstapenko 0. ADAPTATION OF MATHEMATICAL MODEL
OF HEAT AND ENERGY CHARACTERISTICS
OF MEDIUM PRESSURE BOLLER TO REAL
OPERATING CONDITIONS
}

The object of this research is the thermal and energy characteristics of medium-pressure boilers at the thermal power plant of a metallurgical plant operating on a common steam header. The fuel used is a mixture of blast furnace and natural gases. The volume fraction of blast furnace gas is 80-95\%. The characteristics of blast-furnace gas are not constant: the elementary composition, humidity and dust content change significantly.

The mathematical model developed for the purpose of comprehensive optimization of the modes of joint operation of boilers requires adaptation of the energy characteristics obtained by calculation to real operating conditions. Adaptation of the calculated energy characteristics was carried out individually on the basis of thermal balance tests of boilers and taking into account the design and operational features of each boiler. During the tests, the fraction of the convective component of heat transfer in the furnace for the considered boiler units was determined using a non-stationary heat meter. The absolute value of the heat flux density was determined according to the theory of non-stationary regular heating of the sensitive element (SE). It was found that as the fuel burns out, the level of heat fluxes decreases, and with an increase in the thermal fraction of blast furnace gas, the absolute value of local falling fluxes decreases. The average share of the convective component is 15-20\%. It is proposed to adapt to the real operating conditions of the superheater and tail heating surfaces using empirical correction factors obtained during processing of the results of balance tests.

Taking into account the proportion of convective heat flux in the furnace makes it possible to more accurately determine the parameters of the heat carriers along the steam-gas path of the boiler, and, therefore, it is possible to obtain adapted energy characteristics of the boilers. In comparison with analytical calculated dependences, the proposed method provides an individual approach to the operating modes of boilers. Thanks to this, it is possible to reduce the error in determining the optimal solutions to less than $1 \%$.

Keywords: medium pressure boilers, convective heat exchange in the furnace, coefficient of surface heating efficiency.

Received date: 08.04 .2020

Accepted date: 22.05 .2020

Published date: 31.08 .2020
Copyright (c) 2020, Zhitarenko V., Bejan V., Ostapenko O. This is an open access article under the CC BY license (http://creativecommons.org/licenses/by/4.0)

\section{Introduction}

In the last decade, highly efficient combined power plants based on modern cycles and processes have been actively introduced in the thermal power industry. In addition, the widespread use of microelectronics, computer control systems makes it possible to further increase the operational efficiency of both existing power plants and new ones. The rise in prices for primary energy sources, their scarcity require the development and implementation of a wide range of energy saving measures. One of the ways to save energy in the production of thermal energy at combined heat and power plants (CHP) and boiler houses is the choice of optimal operating modes of equipment. Operating modes are largely determined by the characteristics of a specific consumer: daily, weekly and seasonal load schedules, the structure and equipment of existing power supply systems, the technical ability to connect to centralized networks. In addition, it is necessary to take into account circuit designs, characteristics of not only the power plant and other circuit elements, the climatic conditions of the region and much more.

Special attention is paid to the issues of mathematical and technical and economic analysis of the effectiveness of combined technologies, primarily in heat power engineering. The development of approaches to mathematical modeling of such technologies, optimization methods and appropriate software allows to choose effective solutions that ultimately lead to a decrease in production costs.

The power industry began to deal with the solution of optimal problems from the middle of the last century, when large power systems, thermal power plants, combined heat and power plants appeared.

A significant contribution to the formation of optimization processes in the energy sector is shown in studies [1-3]. A fundamental contribution to the theory of optimization of thermal power plants was made in works [4-6]. A number of works of this school have not lost their significance even now [5, 7].

All mentioned works are mainly of a theoretical nature, based on analytical dependencies, therefore, research that 
took into account the real state of heat and power equipment is relevant. The modern use of high-speed personal electronic computers (PC) makes it possible to implement more complex optimization mathematical models and correct them during the time during which changes in energy characteristics occur.

\section{The object of research and its technological audit}

The object of this research is the thermal and energy characteristics of medium-pressure boilers of the combined heat and power plant of a metallurgical plant operating on a common steam collector.

The work investigated the medium pressure boiler block of the combined heat and power plant CHPP-1 of the Private Joint Stock Company (PJSC) «Illich Iron and Steel Works of Mariupol» (Ukraine), which includes 4 boilers CKTI-75/39F2-4 (USSR) and 2 boilers TP-150-2 (USSR). All boilers operate on a common steam collector of $32 \mathrm{~atm}$, $420{ }^{\circ} \mathrm{C}$. The fuel used is a mixture of blast furnace and natural gases with a share of blast furnace gas, which varies in the range of $80-95 \%$. Blast furnace gas characteristics are also changing. The elementary composition, humidity and dust content of blast furnace gas change.

In addition to the above, the specific operating conditions of medium-pressure boilers at CHPP-1 are:

- operation of boilers No. 7-10 on individual chimneys, and two TP-150-2 - on a common chimney;

- the presence in the thermal circuit of CHPP-1 of the

backpressure turbine R-12 (USSR) and parallel to the turbine of standby high-speed reduction-cooling units (SHROU)

between the live steam pipelines $100 \mathrm{~atm}$ and $32 \mathrm{~atm}$;

- on boilers CKTI-75/39F2-4 and TP-150-2, the same

type of direct-flow flat-flare burners (two each) are installed, despite the fact that the productivity and volume of the furnaces differ significantly.

Boiler No. 10 has now been reconstructed by replacing all heating surfaces, lining, instruments and automation. This makes it possible to establish the nature of the change in the operational characteristics of the boiler as the heating surfaces become dirty and worn out.

Fig. 1 shows the changes in the productivity of each of the boilers. Typical for boilers CKTI-75/39F2-4 and TP-150-2, the general nature of the load change during the day is associated with variable operation.

The total interval for changing the productivity of all boilers is $30 \mathrm{t} / \mathrm{h}$, that is, this is the average resource within which the load can be redistributed between boilers.

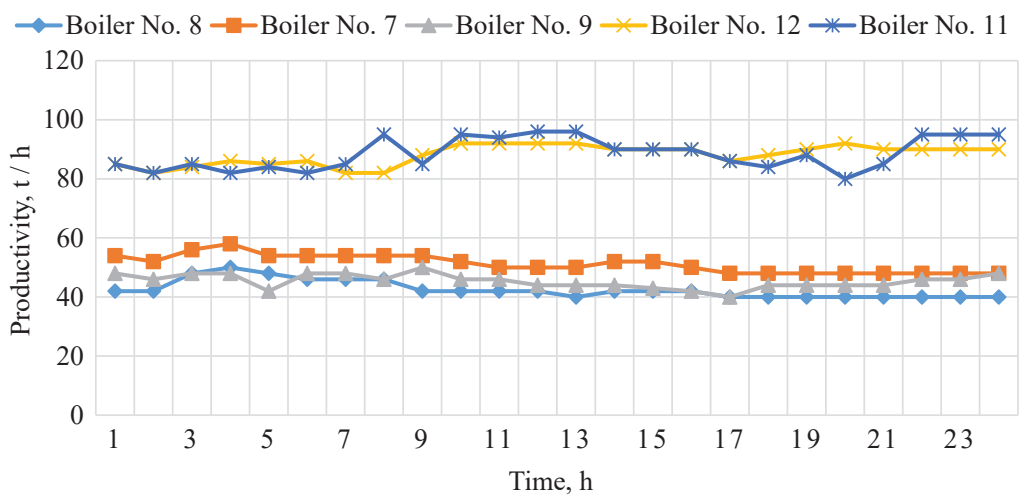

Fig. 1. Change in boiler load during the day

\section{The aim and objectives of research}

The aim of research is to adapt the calculated mathematical model of the boiler in accordance with the parameters of real operating equipment by introducing and determining a number of correction factors based on the results of heat engineering measurements and tests of the boiler.

To do this, it is necessary to do:

1. Correction of the method for calculating heat transfer in the boiler furnace by measuring the proportion of the convective component and its dependence on specific operating factors

2. Correction of the method of calculating heat transfer for convective heating surfaces by introducing and determining the real pollution factors and thermal efficiency of each of the heating surfaces.

3. Determination of empirical coefficients for taking into account the dependence of the suction cup size on the load, fuel composition and the aerodynamic mode of the boiler.

\section{Research of exiting solutions of the problem}

The work [8] presents the results of experimental and numerical studies of the process of coal combustion in a pulverized coal boiler. The pilot focused on optimizing coal combustion to achieve the best performance in the power generation process. The main goal of the work was to increase the efficiency of the boiler based on improved technology for monitoring the operating conditions of boilers. Experimental studies were carried out on an OP-650 pulverized coal boiler located in the EDF Polska Rybnik power plant. The optimization process used modern measuring systems for flue gas temperature distribution and fuel-air distribution. The gas temperature measurement system allows online monitoring of the temperature distribution at the outlet from the furnace. The optimal combustion process was determined by the uniform temperature distribution measured online. However, the work did not take into account the dependence of the boiler efficiency on the combustion modes.

The processes of heat exchange in boilers, taking into account the radiation component, were considered in $[9,10]$. Thermal radiation is a process of internal energy distribution of a radiating body by electromagnetic waves. The study of the influence of particle fractions on the surface of radiant heat transfer in circulating fluidized beds (CFB) is the main one for most. Heat transfer calculations can be extended as well as energy transfer during combustion. The best knowledge of radiative heat transfer can be used to achieve better performance. In the case of using a natural blast-furnace mixture, the combustion products also contain solid particles, but the composition of the gases and the temperature level are somewhat different.

In the study [11], the efficiency of the boiler units of the Mazandaran Cement Plant (Iran) and two methods useful for increasing the efficiency of the boiler, based on the optimization of excess air and the installation of an economizer, are considered. Of the two methods, managing excess air in the boiler was more difficult than using an economizer. 
Under normal conditions, the boiler operated at $55 \%$ of its capacity. At the same time, the amount of excess air and the boiler efficiency were $63.43 \%$ and $77.48 \%$, respectively. Excess air was needed during the combustion process to ensure complete combustion. On the other hand, the minimum heat loss and thus the maximum boiler efficiency was achieved using the optimal level of excess air. The results showed that installing an economizer on a boiler can reduce operating costs by reducing fuel volume. This will also lead to increased boiler efficiency. The work is devoted to stationary modes of boiler operation and does not take into account the effect of excess air on the efficiency under variable modes.

Investigation of the convective component of heat transfer both in furnaces and on heating surfaces is very important. Thus, in [12], measures were considered for the simultaneous calculation of the thermal field both on the side of the masonry and on the side of the wall tubes, as well as at the root walls of the tubes in the convective zone of the boiler. The calculation method allows flexible modeling of heat transfer parameters in the convective zone of the boiler at variable load [13]. The presented techniques are quite complex for variant calculations under variable modes.

Work [14] focuses on the study of the effect of the size of the furnace on the heat transfer mechanism of the burning coal particles. Numerical simulations of coal combustion fields were carried out in three different furnaces (actual large-caliber boilers 915 MW, 2.4 MW and 0.76 MW). The work focuses on coal as a fuel. The high accuracy of the modeling methods was confirmed by the measured data. When comparing numerous simulations between three different boilers, it was found that the settling time of high temperature particles for a small size furnace is shorter than for a larger one even if the residence time of the particles, the high temperature gas passes, is the same.

The inclination angle and type of burner and their effect on nitrogen oxide emissions were considered in [15]. As a burner, a torch burner with a variable angle of combustion of internal secondary air was chosen and a laboratory scale for opposite firing was created. Temperature distribution and $\mathrm{NO}_{x}$ emissions are calculated constructively. Combustion characteristics are experimentally evaluated from ignition and burnup data. Meanwhile, emission reductions are analyzed through measurements. This study examines the various ratios of the concentration of coal and air in the internal and external environments, thermal loads and coal. The results showed the possibility of increasing the intensity of the combustion processes of the coal-air mixture by $10 \%$, depending on the angle of inclination from the load change and at temperatures above $200{ }^{\circ} \mathrm{C}$. The research technique can be used when burning natural blast-furnace mixture in industrial boilers.

Aerodynamic processes and heat exchange in the furnace of a steam boiler with a secondary radiator were considered in studies [16, 17]. For the analysis, water-tube boilers were used, which are common in industrial and municipal boiler houses, and they are used as sources of heat and steam supply. The implementation of measures to ensure environmental efficiency at an acceptable level, the use of modern burners and the automation of boilers for worn out and outdated boiler structures that require significant reconstruction and significant financial costs were analyzed. The results of a numerical study of heat transfer processes during the combustion of fossil fuels have shown the effectiveness of placing a secondary tubular reversible radiator in the volume of the boiler furnace. It was found that the density of the radiant heat flux increases by $15-20 \%$, the temperature of the flue gases at the outlet from the furnace decreases and amounts to $970{ }^{\circ} \mathrm{C}$. The dimensions of the flame of the torch exclude its collision with the surfaces of the shielded pipes. During the combustion of the gas mixture, the concentration of nitrogen oxides at the outlet of the boiler furnace does not exceed $125 \mathrm{mg} / \mathrm{m}^{3}$. In this case, the numerical study of heat transfer in the boiler furnace is suitable mainly for fossil fuels and does not take into account the peculiarities of combustion of low-calorific gases.

In the above studies, the authors have modeled the energy characteristics of boiler units and determined the influence of various operating parameters on the efficiency of boilers. However, an experimental study, taking into account the operating parameters of operating boilers and determining the influence of the convective component, was not carried out, which emphasizes the prospects of research.

\section{Methods of research}

The fraction of the convective component was determined using an unsteady heat meter. A diagram of a non-stationary heat meter is shown in Fig. 2. The nonstationary heat meter consists of a body 3 , in which a sensitive element (SE) 5 is pressed, which is cylinder made of steel X18H9T. A chromel-alumel thermocouple is inserted into the sensing element. The holder 1 is welded to the body, with the help of which the heat meter is placed into the boiler furnace. The heat meter is made according to the design and recommendations given in $[18,19]$.

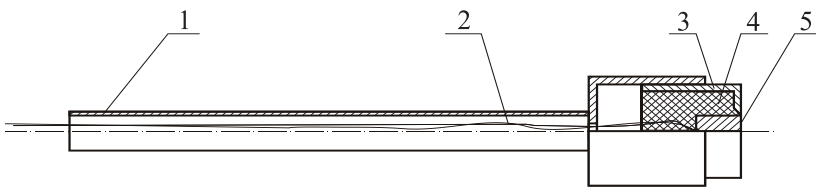

Fig. 2. Scheme of a non-stationary heat meter: 1 - holder; 2 - thermocouple leads; 3 - body; 4 - heat insulating filler 5 - sensitive element

The heat meter was introduced into the furnace through the hatches in such a way that the end surface of the heat meter with the SE was in the same plane with the wall tubes. The convective component was determined from the ratio of heat fluxes incident on the sensitive element with mirror-like and blackened surfaces. The blackening of the SE surface was carried out with a mixture of soot and BF glue. Such a surface has a blackness of $0.97-0.98$. The polished SE surface made of steel X18H9T has a blackness degree of $0.08-0.09$.

The absolute value of the heat flux density was determined according to the theory of non-stationary regular heating of the SE by measuring the time interval during which the SE temperature increased from 100 to $150{ }^{\circ} \mathrm{C}$. The temperature was recorded with a digital thermometer with an error of $0.5{ }^{\circ} \mathrm{C}$, and the time was recorded with a stopwatch.

The regular mode of temperature variation in time is linear at an arbitrary point of the SE for two points in time. For SE with a surface emissivity close to 1 : 


$$
\alpha_{l}+\alpha_{c}=\frac{\left(\ln \theta_{1}-\ln \theta_{2}\right)}{\Delta \tau_{r} F_{m}} \rho_{m} c_{m} V \psi_{r}
$$

where $\alpha$ - the coefficient of heat transfer by radiation and convection, respectively; $\theta_{1}, \theta_{2}-\mathrm{SE}$ temperatures at the end and at the beginning of heating; $\Delta \tau-\mathrm{SE}$ heating time; $\psi$ - coefficient of non-uniformity of the SE temperature field; $\rho_{m}, c_{m}, F_{m}, V$ - density, heat capacity, heat exchange area and SE volume of SE material; $r$ and $c$-indices that relate to heat transfer by radiation and convection.

For SE with a surface emissivity close to zero:

$$
\alpha_{c}=\frac{\left(\ln \theta_{1}-\ln \theta_{2}\right)}{\Delta \tau_{c} F_{m}} \rho_{m} c_{m} V \psi_{c} .
$$

Preliminary calculations showed that $\alpha_{c} \approx 0.25 \alpha_{r}$, the ratio of the coefficients of non-uniformity of SE temperature fields is $\psi_{c} \approx 0.94 \psi_{r}$.

Accordingly, with the same temperature range for SE heating, let's obtain:

$$
\frac{\alpha_{l}+\alpha_{c}}{\alpha_{c}}=\frac{\Delta \tau_{c}}{\Delta \tau_{r}} \frac{\psi_{r}}{\psi_{c}}
$$

or the proportion of the convective component in the total heat flux:

$$
\frac{q_{c}}{q_{r}}=1-\frac{\alpha_{l}}{\alpha_{r}}=1-\frac{\Delta \tau_{r}}{\Delta \tau_{l}} \frac{\psi_{l}}{\psi_{r}}
$$

In this case, it is necessary to take into account the coefficient of transition from ablution of a flat surface (SE heat meter) to ablution of a cylindrical surface (shield tube). According to $[19,20]$, this coefficient is about 0.7 .

The final calculation of the fraction of the convective component was carried out according to the formula:

$$
\frac{q_{c}}{q_{r}}=0.7\left(1-0.94 \frac{\Delta \tau_{r}}{\Delta \tau_{l}}\right) .
$$

Fig. 3 shows the points of measurement of local heat fluxes in the furnace of boilers CKTI-75 and TP-150.

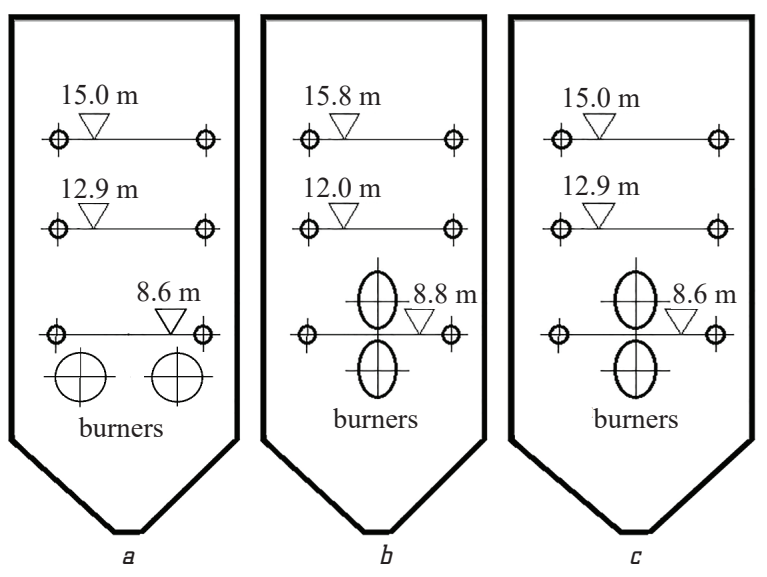

Fig. 3. Schemes for measuring heat fluxes on boilers: $a$ - TP 150-2; $b$ - CKTI-75/39F2-4 No. 7, 9;

\begin{tabular}{|c|c|c|c|c|}
\hline \multicolumn{5}{|c|}{ CKTI-75/39F2-4 No. 7 boiler } \\
\hline $\begin{array}{c}\text { Measurement } \\
\text { location }\end{array}$ & $\begin{array}{l}\text { Level } \\
8.6 \mathrm{~m} \\
\end{array}$ & $\begin{array}{c}\text { Level } \\
12.9 \mathrm{~m} \\
\end{array}$ & $\begin{array}{c}\text { Level } \\
15.0 \mathrm{~m} \\
\end{array}$ & Mode \\
\hline $\begin{array}{c}\text { Proportion of } \\
\text { the convective } \\
\text { component }\end{array}$ & 0.224 & 0.18 & 0.11 & $\begin{array}{c}D=38 \mathrm{t} / \mathrm{h} \\
B_{d g}=36000 \mathrm{~m}^{3} / \mathrm{h} \\
B_{p g}=750 \mathrm{~m}^{3} / \mathrm{h}\end{array}$ \\
\hline \multicolumn{5}{|c|}{ CKTI-75/39F2-4 No. 8 boiler } \\
\hline $\begin{array}{c}\text { Measurement } \\
\text { location }\end{array}$ & $\begin{array}{l}\text { Level } \\
8.6 \mathrm{~m}\end{array}$ & $\begin{array}{c}\text { Level } \\
12.9 \mathrm{~m}\end{array}$ & $\begin{array}{l}\text { Level } \\
15.0 \mathrm{~m}\end{array}$ & Mode \\
\hline $\begin{array}{l}\text { Proportion of } \\
\text { the convective } \\
\text { component }\end{array}$ & 0.264 & 0.224 & 0.16 & $\begin{array}{c}D=37 \mathrm{t} / \mathrm{h} \\
B_{d g}=33000 \mathrm{~m}^{3} / \mathrm{h} \\
B_{p g}=620 \mathrm{~m}^{3} / \mathrm{h}\end{array}$ \\
\hline \multicolumn{5}{|c|}{ CKTI-75/39F2-4 No. 9 boiler } \\
\hline $\begin{array}{c}\text { Measurement } \\
\text { location }\end{array}$ & $\begin{array}{l}\text { Level } \\
8.6 \mathrm{~m}\end{array}$ & $\begin{array}{c}\text { Level } \\
12.9 \mathrm{~m}\end{array}$ & $\begin{array}{c}\text { Level } \\
15.0 \mathrm{~m}\end{array}$ & Mode \\
\hline $\begin{array}{l}\text { Proportion of } \\
\text { the convective } \\
\text { component }\end{array}$ & 0.182 & 0.15 & 0.08 & $\begin{array}{c}D=34 \mathrm{t} / \mathrm{h} \\
B_{d g}=27000 \mathrm{~m}^{3} / \mathrm{h} \\
B_{p g}=820 \mathrm{~m}^{3} / \mathrm{h}\end{array}$ \\
\hline \multicolumn{5}{|c|}{ TP 150-2 No. 11 boiler } \\
\hline $\begin{array}{c}\text { Measurement } \\
\text { location }\end{array}$ & $\begin{array}{l}\text { Level } \\
8.6 \mathrm{~m} \\
\end{array}$ & $\begin{array}{c}\text { Level } \\
12.9 \mathrm{~m} \\
\end{array}$ & $\begin{array}{c}\text { Level } \\
15.0 \mathrm{~m} \\
\end{array}$ & Mode \\
\hline $\begin{array}{c}\text { Proportion of } \\
\text { the convective } \\
\text { component }\end{array}$ & 0.18 & 0.11 & 0.05 & $\begin{array}{c}D=76 \mathrm{t} / \mathrm{h} \\
B_{d g}=60000 \mathrm{~m}^{3} / \mathrm{h} \\
B_{p g}=500 \mathrm{~m}^{3} / \mathrm{h}\end{array}$ \\
\hline \multicolumn{5}{|c|}{ TP 150-2 No. 12 boiler } \\
\hline $\begin{array}{c}\text { Measurement } \\
\text { location }\end{array}$ & $\begin{array}{l}\text { Level } \\
8.8 \mathrm{~m} \\
\end{array}$ & $\begin{array}{c}\text { Level } \\
12.0 \mathrm{~m} \\
\end{array}$ & $\begin{array}{c}\text { Level } \\
15.8 \mathrm{~m} \\
\end{array}$ & Mode \\
\hline $\begin{array}{l}\text { Proportion of } \\
\text { the convective } \\
\text { component }\end{array}$ & 0.22 & 0.14 & 0.08 & $\begin{array}{c}D=80 \mathrm{t} / \mathrm{h} \\
B_{d g}=68000 \mathrm{~m}^{3} / \mathrm{h} \\
B_{p g}=750 \mathrm{~m}^{3} / \mathrm{h}\end{array}$ \\
\hline
\end{tabular}
c - CKTI-75/39F2-4 No. 8, 10

Table 1 shows the results of measurements of heat fluxes and convective components.
Table 1

For the developed mathematical model, it was not the absolute value of the heat flux in the furnace that was important, but the fraction of the convective component. Since it was necessary to confirm the validity of the application of the methodology for calculating complex heat exchange in the furnace when burning a mixture of natural and blast furnace gases.

The maximum level of falling fluxes is fixed at the level of the burners. As the fuel burns out, the level of heat flux decreases. With an increase in the thermal fraction of blast furnace gas, the absolute value of local falling fluxes decreases. The average share of the convective component is $15-20 \%$.

\section{Research results}

6.1. Methodology for accounting the peculiarities of heat transfer in the furnace. When a significant amount of blast furnace gas is burned in a mixture with highcalorific natural gas, heat exchange between the torch and the screens occurs at low torch temperatures and relatively high gas flow rates.

The specificity of burning gaseous fuels in flat-flame burners (boilers CKTI-75/39F2-4 No. 7, 9 and TP 150-2 No. 11, 12), especially with an increase in the share of blast furnace gas, creates increased velocities in the near-wall zone of the combustion chamber. This fact is confirmed visually, especially in the furnaces of boilers CKTI-75/39F2-4. Due to the relatively small volume of the furnace, turbulent eddies are observed and high heat fluxes take place. Thus, in 
the case of predominant combustion of blast-furnace gas at relatively low temperatures in the torch core, the proportion of convective heat exchange with screens is significant.

The application of the main provisions of the «normative method» [21] for calculating single-chamber furnaces with flat-flame and vortex burners when burning a blastfurnace-natural mixture showed that it does not sufficiently take into account the conditions of complex heat transfer, namely, convective heat transfer to the screens. To determine the heat transfer coefficient to the wall tubes, let's use the criterion dependence for the longitudinal turbulent flow around the heating surfaces [21]:

$$
N u_{s c r}=0.023 \operatorname{Re}_{s c r}^{0.8} \operatorname{Pr}_{s c r}^{0.4}
$$

where $N u_{\text {scr }}$ - Nusselt criterion for the gas flow, which washes the screen pipes; $\mathrm{Re}_{s c r}-$ Reynolds criterion for gas flow, which washes the screen tubes; $\operatorname{Pr}_{s c r}$ - Prandtl criterion for the same stream. The value of these criteria is determined according to the well-known method for calculating heat transfer.

Taking into account the fact that in the investigated range of temperature variation of flue gases the value of the Prandtl criterion is practically constant and equal to 0.56, expression (6) takes the form:

$$
N u_{s c r}=0.018 \operatorname{Re}_{s c r}^{0.8}
$$

Heat flux in screen tubes. The value $q_{c}^{s c r}$ can be written down:

$$
q_{c}^{s c r}=\alpha_{c}^{s c r}\left(T_{f}-T_{w}^{c}\right),
$$

where $\alpha_{c}^{s c r}$ - coefficient of heat transfer from gases to the pipe wall; $T_{f}, T_{w}^{s c r}$ - flame temperature and the temperature of the outer wall of the pipe, respectively.

Calculation by formula (8) showed that the proportion of heat absorption in the furnace of the CKTI-75/39F2-4 boiler due to convection in the range of variation of the thermal fraction of blast furnace gas from 0 to 0.8 varies from 10 to $30 \%$.

Taking into account the significant level of convective heat absorption in the furnaces of CHP boilers when burning a mixture of fuels with different heats of combustion, it is necessary to take it into account when calculating combustion chambers operating under similar conditions. According to the «normative method», the heat transferred by convection is determined by the formula:

$$
Q_{c}=\frac{\bar{\alpha}_{c}^{s c r} H_{c}\left(T_{f}-T_{w}\right)}{B_{e}},
$$

where $\bar{\alpha}_{c}^{s c r}-$ coefficient of heat transfer by convection to the wall tubes; $T_{f}$ - effective temperature of the combustion medium; $T_{w}$ - the temperature of the contaminated surface wall perceives radiant energy; $H_{c}$ - heating surface, which perceives radiant energy; $B_{e}$ - estimated fuel consumption.

At the same time, when calculating convective heat transfer using formula (9), it is necessary to take into account the fact that the generalized heat transfer coefficient to the screens $\bar{\alpha}_{c}^{s c r}$ should be related to the surface, washed by flue gases directly. In general, this surface differs from the surface of the screens, they perceive radiant energy by about $10 \%$.
The calculation of heat transfer in the furnace, taking into account the heat transfer by convection during combustion of a mixture of blast furnace and natural gases in the mathematical model, was carried out according to the following method. In this case, the calculation basis of the method is a system of equations describing heat exchange in the furnace. It includes the equations of radiation heat exchange of the combustion medium with heating surfaces:

$$
Q_{l}=\frac{\delta_{0} \varepsilon_{c} H_{l}}{B_{e}}\left(T_{f}^{4}-T_{w}^{4}\right),
$$

where $\delta_{0}$ - emissivity of an absolutely black body; $H_{l}-$ exchangeable heating surface; $T_{f}$ - effective temperature of the combustion medium; $T_{w}$ - temperature of the contaminated surface wall, which perceives radiant energy; $B_{e}$ - estimated fuel consumption; $\varepsilon_{c}$ - reduced degree of furnace emissivity.

According to [21], the reduced emissivity is determined by the formula:

$$
\varepsilon_{c}=\frac{1}{\frac{1}{\varepsilon_{n}}+\chi\left(\frac{1}{\varepsilon_{f}}-1\right)},
$$

where $\varepsilon_{l}$ - effective absorbing capacity of the smooth-tube screens; $\varepsilon_{f}$ - blackness degree of the torch; $\chi$ - shielding degree of the combustion chamber.

With the upper input of blast furnace gas, $T_{f}$ is calculated as follows [20, 22]: 
The calculation of the temperature at the outlet of the combustion chamber is performed by the method of successive approximations in accordance with the generally accepted method. Comparison of the temperature at the outlet from the furnace, calculated by the proposed method with the experimental values, indicates a good agreement between the experimental and calculated data.

6.2. Determination of efficiency factors of heating surfaces. One of the hard to predict factors when comparing the experimental and calculated characteristics of boilers are the efficiency and contamination coefficients of heating surfaces. In this work, the adaptation of the mathematical model is carried out by introducing into the calculation of the correction factors found experimentally and analytically for the operating equipment.

The amount of heat absorbed by the water in the economizer:

$$
Q=D_{f w}\left(i_{o u t}-i_{\text {in }}\right),
$$

where the consumption of feed water $D_{f w}$, which is determined by the panel device; $i_{\text {out }}$ and $i_{\text {in }}$ - direct measurements of the temperature of the heat carrier (water).

The correction factor $\chi_{s c r}$ is included in the heat transfer equations at the heating surface:

$$
Q=\chi_{\text {scr }} k_{\text {theor }} \Delta t_{\text {count }} H_{\text {calc }},
$$

where $\Delta t_{\text {count }}$ - temperature head on the surface for ideal counterflow; $H_{\text {calc }}$ - area of the heat-absorbing surface, determined according to the drawings of the boiler; $K_{\text {theor }}-$ calculated heat transfer coefficient.

The correction factor includes:

- correction for a decrease in the heat exchange area $H_{\text {calc }}$, since part of the tubes during operation can be plugged:

$h_{e k}=\frac{H_{\text {real }}}{H_{\text {calc }}}$;

- coefficient of efficiency of the heating surface $\xi_{s c r}$, which can be greater or less than the standard;

- the coefficient of transition to a complex heat exchange scheme $\psi_{s c r}$ is determined for the adopted scheme of the movement of heat carriers in terms of temperature differences. Correction factor:

$$
\chi_{s c r}=\xi_{s c r} \cdot h_{s c r} \cdot \psi_{s c r}=\frac{D_{f w}\left(i_{\text {out }}-i_{\text {in }}\right)}{K_{\text {theor }} \Delta t_{\text {count }} H_{\text {calc }}} .
$$

For air heaters:

$$
Q_{a b}=V_{a}\left(\left(c_{a} t\right)_{\text {out }}-\left(c_{h} t\right)_{\text {in }}\right) .
$$

Correction factor for air heaters:

$$
\chi_{a b}=\xi_{a b} \cdot h_{a b} \cdot \psi_{a b}=\frac{V_{a}\left(\left(c_{a} t\right)_{\text {out }}-\left(c_{h} t\right)_{\text {in }}\right)}{K_{\text {theor }} \Delta t_{\text {count }} H_{\text {calc }}} .
$$

The value of the temperature difference is calculated according to the usual method for counterflow:

$$
\Delta t_{\text {count }}=\frac{\Delta t_{b}-\Delta t_{m}}{\ln \frac{\Delta t_{b}}{\Delta t_{m}}} .
$$

The values $k_{\text {theor }}$ were calculated according to the normative method [21] as for the case without taking into account the negative factors of operation.

The found values $\chi$ were then entered into the mathematical model. The verification of the conformity of the thermal efficiency coefficients is carried out with the coincidence of the temperature distribution in the gas, air, steam-water paths of the boiler during the calculation and according to the test results of one basic mode. According to the described method, the values $\chi_{s c r}$ and $\chi_{s w}$ were determined for boilers TP-150-2 (No. 11, 12), CKTI-75/39F2-4 (No. 7-9).

6.3. Analysis of the properties of blast furnace gas and their influence on the efficiency of boilers. Blast furnace gas at CHPP-1 is supplied from an off-site collector with a composition averaged over all blast furnaces. The gas has a high humidity (up to 90-100\%) and in some periods - a fairly high dust content. Its average temperature fluctuates in the range of $35-65{ }^{\circ} \mathrm{C}$.

One of the difficulties in the operational distribution of loads between boilers that burn blast furnace gas and their mixtures is the variable value of the composition and the heat of combustion. The nature of the influence of the composition and the heat of combustion on the efficiency is unambiguous: with a decrease in the heat of combustion, the efficiency of the boiler decreases. Moreover, the heat of combustion of blast furnace gas affects to a greater extent than the composition.

The heat and composition of the blast furnace gas changes significantly in the daily and annual sections. This is due to the operation of blast furnaces and gas purifiers. There are no calorimeters for determining the heat of combustion of blast furnace gas at CHPP-1. Changes in the composition and heat of combustion of blast furnace gas were analyzed according to the data of the gas analysis laboratory of the plant. Fig. 4 shows the nature of the change in the heat of blast furnace gas over the past two years. No explicit seasonal dependences of the calorific value and gas composition have been established. Since the composition of the gas depends on many factors (the supply and quality of coke, the composition of the charge, the course of the furnace, etc.), it is not possible to predict the characteristics of the blast furnace gas.

To take into account the properties of blast furnace gas when optimizing loads, it is possible to go in two ways:

- to install a calorimeter at CHPP-1, receive operational information on the properties of blast furnace gas and adjust the optimal loads in accordance with it;

- to distribute the loads according to the average composition and the heat of combustion, and when they change, introduce correction factors. In this work, the second way is used. Based on the results of the analysis of changes in the composition of blast furnace gas, the average composition of the gas and the heat of combustion were determined as $\mathrm{CO}=24.15 \%, \mathrm{CO}_{2}=15.97 \%$, $\mathrm{H}_{2}=5.7 \%$. Calorific value $-817 \mathrm{kcal} / \mathrm{m}^{3}$. 


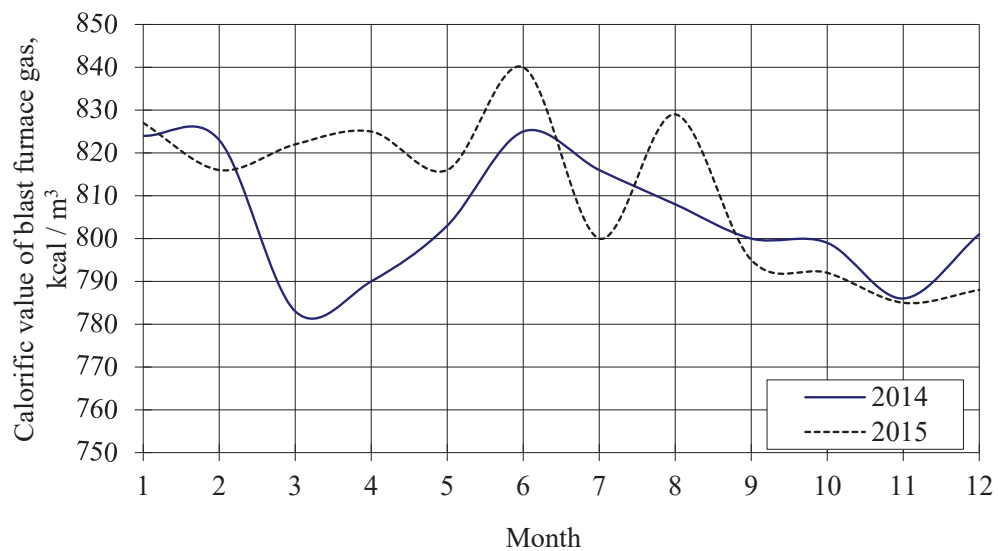

Fig. 4. Change in the heat of combustion of blast furnace gas during the year

\section{SWOT analysis of research results}

Strengths. The strength of this research is the adaptation of the developed theoretical model for calculating heat transfer. Experimental studies carried out on real boilers confirm the theoretical conclusions on improving the energy efficiency of medium pressure boilers.

Weaknesses. Weaknesses include the need for initial capital costs to analyze the system where the implementation of certain measures is planned. This study examines boilers after conversion from solid fuel to mixed gas. The heat and composition of the blast furnace gas changes significantly in the daily and annual sections. This is due to the operation of blast furnaces and gas purifiers. There are no calorimeters for determining the heat of combustion of blast furnace gas at CHPP-1. For a more accurate analysis, it is necessary to additionally provide the enterprise with measures to assess the composition of the fuel and the load on the boiler units at a specific point in time.

Opportunities. The conducted research is based on operating boilers after conversion from solid fuel to liquid fuel (a mixture of natural and blast-furnace gases). Based on it, it is possible to calculate the heat transfer in the furnace, taking into account the convective part of the heat transfer in the furnace. This, in turn, will improve the efficiency of existing systems and will improve equipment replacement.

Threats. An enterprise, a CHPP or a boiler house will require capital investments to analyze the boiler equipment and operating parameters.

\section{Conclusions}

1. According to the developed method of measuring the proportion of the convective component in the furnace, which averaged $20-25 \%$. The peculiarities of heat exchange in the furnace were taken into account according to a special method developed for calculations for flatflame combustion of a natural blast-furnace mixture.

2. Tests of TP-150-2 and CKTI-75/39F2-4 boilers in the main operating modes allowed to determine the true coefficients of efficiency and contamination of convective heating surfaces. Their values turned out to be 1.2-1.5 times lower than those recommended by the normative methods.

3. Based on the obtained experimental coefficients of efficiency and contamination of heating surfaces, the adap- tation of the mathematical model to real conditions was carried out. Analysis of the calculation and test results showed sufficient convergence for most parameters. This makes it possible to calculate the performance of boilers in all operating modes.

\section{References}

1. Gornshtein, V., Miroshnichenko, B., Ponomarev, A. et. al. (1981) Metody optimizatsii rezhimov energosistem. Moscow: Energiia, 336.

2. Venikov, V., Zhuravlev, V., Filippova, T. (1990). Optimizatsiia rezhimov elektrostantsii i energosistem. Moscow: Energoatomizdat, 352.

3. Andriuschenko, A., Zmachinskii, A., Poniatov, V. (1974). Optimizatsiia teplovykh tsiklov i protsessov TES. Moscow: Vysshaia shkola, 279

4. Andriuschenko, A., Aminov, R. (1983). Optimizatsiia rezhimoz raboty i parametrov teplovykh elektrostantsii. Moscow: Vysshaia shkola, 255.

5. Aminov, R. (1994). Vektornaia optimizatsiia rezhimov raboty elektrostantsii. Moscow: Energoatomizdat, 304.

6. Kalikhman, I., Voitenko, M. (1979). Dinamicheskoe programmirovanie v primerakh i zadachakh. Moscow: Vysshaia shkola, 125.

7. Barochkin, E., Zhukov, V., Ulanov, D. (2009). Raspredelenie nagruzki mezhdu turboagregatami teploelektrotsentrali s ispolzovaniem printsipa optimalnosti Belmana. Vestnik IGEU, 3, 11-14.

8. Madejski, P., Janda, T., Modlinski, N., Nabaglo, D. (2016). A Combustion Process Optimization and Numerical Analysis for the Low Emission Operation of Pulverized Coal-Fired Boiler. Developments in Combustion Technology, 33-76. doi: http:// doi.org/10.5772/64442

9. Maximov, A. (2008). Radiative Heat Transfer In Boiler Furnaces. Lappeenranta, 85. Available at: https://lutpub.lut.fi/ bitstream/handle/10024/42028/nbnfi-fe200808041751.pdf?sequence $=1 \&$ is Allowed $=\mathrm{y}$

10. Bordbar, H., Hyppänen, T. (2007). Modeling of Radiation Heat Transfer in a Boiler Furnace. Advanced Studies in Theoretical Physics, 1 (12), 571.

11. Mehdizadeh, H., Alishah, A., Astani, S. H. (2016). Study on performance and methods to optimize thermal oil boiler efficiency in cement industry. Energy Equipment and Systems, 4 (1), 53-64

12. Gómez, A., Fueyo, N., Díez, L. I. (2008). Modelling and simulation of fluid flow and heat transfer in the convective zone of a power-generation boiler. Applied Thermal Engineering, 28 (5-6), 532-546. doi: http://doi.org/10.1016/j.applthermaleng.2007.04.019

13. Redko, A., Dzhyoiev, R., Davidenko, A., Pavlovskaya, A., Pavlovskiy, S., Redko, I. et. al. (2019). Aerodynamic processes and heat exchange in the furnace of a steam boiler with a secondary emitter. Alexandria Engineering Journal, 58 (1), 89-101. doi: http://doi.org/10.1016/j.aej.2018.12.006

14. Hashimoto, N., Watanabe, H. (2016). Numerical analysis on effect of furnace scale on heat transfer mechanism of coal particles in pulverized coal combustion field. Fuel Processing Technology, 145, 20-30. doi: http://doi.org/10.1016/j.fuproc.2016.01.024 
15. Zhang, Y., Luo, R., Dou, Y., Zhou, Q. (2018). Combustion Characteristics and NOx Emission through a Swirling Burner with Adjustable Flaring Angle. Energies, 11 (8), 2173. doi: http:// doi.org/10.3390/en11082173

16. Zhang, Y., Li, Q., Zhou, H. (2016). Heat Transfer Calculation in Furnaces. Theory and Calculation of Heat Transfer in Furnaces, 131-172. doi: http://doi.org/10.1016/b978-0-12800966-6.00005-3

17. Rahmani, A. (2014). Numerical Investigation of Heat Transfer in 4-Pass Fire-Tube Boiler. American Journal of Chemical Engineering, 2 (5), 65. doi: http://doi.org/10.11648/j.ajche.20140205.12

18. RD 34.09.155-93. Metodicheskie ukazaniia po sostavleniiu $i$ soderzhaniiu energeticheskikh kharakteristik oborudovaniia teplovykh elektrostantsii (1999). Moscow: SPO ORGRES. Available at: http://docs.cntd.ru/document/1200039161

19. Trembovlia, V., Finger, E. (1991). Teplotekhnicheskie ispytaniia kotelnykh ustanovok. Moscow: Energoatomizdat, 416.

20. Danilin, E., Klochkov, V. (1988). Kontrol szhiganiia topliva v promyshlennykh kotelnykh ustanozkakh. Kyiv: Tekhnika, 167.
21. Teplovoi raschet kotlov (normativnii metod) (1998). Saint Petersburg: NPO TSKTI, 256.

22. Teplovye ispytaniia kotla PK-14-2M Magnitogorskogo MK. Tekhnicheskii otchet (1988). Leningrad: TSECHM.

Zhitarenko Volodymyr, Senior Lecturer, Department of Industrial of Thermal Power Plants and of Thermal Supply, Priazov State Technical University, Mariupol, Ukraine,e-mail: zom0309@ukr.net, ORCID: https://orcid.org/0000-0003-1417-5373

Bejan Volodymyr, PhD, Associate Professor, Department of the Industrial of Thermal Power Plants and of Thermal Supply, Priazov State Technical University, Mariupol,Ukraine,e-mail:azovbis@ukr.net ORCID: https://orcid.org/0000-0003-4046-5999

Ostapenko Oleksij, PhD, Senior Lecturer, Department of Refrigeration Technique and of Conditioning of Air, Odesa National Academy of Food Technologies, Ukraine, e-mail: ostapenkosc@gmail.com, ORCID: https://orcid.org/0000-0002-2903-6918 